\title{
LA ENSEÑANZA DE LAS LENGUAS INDÍGENAS EN COSTA RICA
}

\section{Carmen Rojas Chaves*}

En Costa Rica se reconocen seis lenguas indigenas que actualmente muestran un gran debilitamiento por la llamada "nación unificada" bajo una sola lengua y una sola cultura.

Ante esta situación, Costa Rica ha ratificado convenios internacionales para la conservación y difusión de las lenguas y las culturas autóctonas y la educación del niño indígena.

El Programa de Enseñanza de las Lenguas Indigenas en nuestro país busca dar un espacio para la transmisión y recuperación de sus elementos culturales a pesarde los obstáculos administrativos, legales, mentales y culturales que permitan asumir la diversidad cultural.
In Costa Rica there are six indigenous languages which currently are becoming weaker due to the so-called "unified nation" with one language and one culture. Due to this situation, Costa Rica has ratified international agreements to conserve and spread autochthonous languages and cultures, along with promoting the education of indigenous children.

The Program for the Teaching of Indigenous Languages in our country is trying to develop a way to transfer and recover cultural elements in spite of administrative, legal, mental and cultural obstacles to cultural diversity:

* Máster en Lingüística por la Universidad de Costa Rica, bachiller en enseñanza del Castellano y bachiller en Filología Española. Con amplia experiencia en lenguas indígenas y educación intercultural bilingüe, coordina el Programa de Enseñanza de las Lenguas Indígenas del Departamento de Educación Indígena del Ministerio de Educación Pública. carmenr@racsa.co.cr. 


\section{Culturas indígenas de Costa Rica}

En Costa Rica existen 8 culturas indígenas, distribuidas en 24 territorios indígenas legalmente constituidos.

De acuerdo con el censo del año 2000, la población indígena del país es de 63800 personas, de las cuales, un $42 \%$ vive dentro de los territorios indígenas y un $58 \%$ vive fuera de territorios indigenas (un $31 \%$ en zonas rurales, generalmente cercanas a los territorios indígenas y un $27 \%$ en el resto del país). Un $21 \%$ de los indígenas vive en zonas urbanas.

La población indígena, entonces, constituye un $1,7 \%$ de los casi 4 millones de personas que habitamos este país.

\section{Lenguas indigenas de Costa Rica}

En Costa Rica oficialmente se reconoce la existencia de 6 lenguas indígenas, aunque en realidad se hablan 8 , porque con el término "guaymí" se encierran dos lenguas (el ngäbére y el buglére) y también hay un importante grupo de misquitos que mantiene su lengua.

El huetar -la que parece haber sido la lengua franca a la llegada de los españoles - y el chorotega o mangue son dos lenguas que se extinguieron en los últimos siglos.

Las 6 lenguas indígenas, cuya existencia es reconocida son: el bribri, el cabécar, el guaymí, el malecu o guatuso, el boruca o brunca y el térraba. Las dos últimas están en proceso de extinción y entre las restantes hay diversos niveles de mantenimiento, que varían incluso de una comunidad a otra, e inclusive, entre las familias de una misma comunidad.

Por esta razón, los niños ingresan a la escuela con diferentes niveles de conocimiento y uso de su lengua autóctona y del español: un $50 \%$ es monolingüe en la lengua indígena, no habla español o no lo hace de manera funcional; un $40 \%$ son monolingüe en español, es decir, no habla ninguna lengua indígena y un $10 \%$ posee un bilingüismo coordinado, es decir, se comunica fluidamente con igual eficiencia y eficacia en ambas lenguas.

En el presente, todas las lenguas indigenas muestran un gran debilitamiento en relación con los siglos pasados, situación que va de la mano con la declinación, e incluso, pérdida de muchos de los rasgos culturales propios de los pueblos indígenas.

Esa es una de las razones por las que las comunidades indígenas, que en décadas anteriores habian mostrado una actitud pasiva e indiferente ante la pérdida cultural y lingüística, han empezado a mostrar una gran preocupación y a realizar esfuerzos y acciones concretas, buscando detener ese proceso. 
Una de las razones que han contribuido a crear una situación desfavorable para las lenguas indigenas es la idea republicana de crear una nación unificada, uniforme, reunida bajo una sola lengua y una cultura "nacional". Esta idea no sólo ha excluido a otros grupos, sino que incluso ha llevado al cuestionamiento legal de permitir la expresión de las culturas y lenguas de grupos minoritarios. Por esta razón, estimo conveniente hacer una breve mención a la legislación en favor de las lenguas indigenas.

Legislación en favor de las lenguas indígenas

Costa Rica ha ratificado convenios internacionales que comprenden artículos que protegen derechos de las minorías, como la Convención de los Derechos de los Niños y de las Niñas (1990), asi como el Convenio 169 de la Organización Internacional del Trabajo (OIT) (1992).

La Convención de los Derechos de los Niños y de las Niñas, en su artículo 30, establece que:

"En los países en que existan minorías étnicas, religiosas o lingüísticas o personas de origen indígena, no se negará a un niño que pertenezca a tales minorías o que sea indígena, el derecho que le corresponde, de común con los demás miembros de su grupo, a tener su propia vida cultural, a profesar y practicar su propia religión, o a emplear su propio idioma".

Cuando Costa Rica ratifica el Convenio 169 de la OIT, se compromete, en materia educativa, a lo siguiente:

"Los programas y los servicios de educación destinados a los pueblos interesados deberán desarrollarse y aplicarse en cooperación con éstos a fin de responder a sus necesidades particulares, y deberán abarcar su historia, sus conocimientos y técnicas, sus sistemas de valores y todas sus demás aspiraciones sociales, económicas y culturales". (Artículo 27).

"Siempre que sea viable, deberá enseñarse a los niños de los pueblos interesados a leer y a escribir en su propia lengua indigena o en la lengua que más comúnmente se hable en el grupo a que pertenezca. Cuando ello no sea viable, las autoridades competentes deberán celebrar consultas con esos pueblos con miras a la adopción de medidas que permitan alcanzar este objetivo". (Artículo 28). 
“Deberán adoptarse disposiciones para preservar las lenguas indígenas de los pueblos interesados y promover el desarrollo y la práctica de las mismas" (Artículo 28).

A partir de la ratificación de este Convenio, en el país se ha venido creando jurisprudencia en materia educativa. Un ejemplo de esto, lo encontramos en los argumentos de la Sala Constitucional para rechazar la acción de inconstitucionalidad presentada por la ACEP en contra del Decreto Ejecutivo $N^{\circ} 27740$ MEP del 19 de enero de 1999 y otros (Expediente $N^{\circ} 8306-0007-C O$ ), que entre otros puntos señala:

a) Dicho artículo (artículo 30 de la Convención de los Derechos del Niño) consagra el derecho de las minorías linguiísticas y de las personas de origen indigena de educarse en su propia lengua, utilizando su idioma (p. 8).

b) Discriminación puede ser exigirle a un miembro de una minoría lingüística y étnica que realice sus exámenes en idioma español y más aún, es el negarle el derecho a educarse y conocer su propia lengua (p. 9).

c) Respecto del Decreto N. 27740 MEP de cita, la Procuraduría reitera que Costa Rica no es un país bilingüe, aunque se reconoce el derecho de los pueblos indígenas a que sus miembros se eduquen en la lengua maternal, lo que en el fondo ayuda a preservar el acervo cultural de la Nación y no sólo del pueblo indígena. Para esos niños que sí tienen una lengua diferente del español, el derecho a la educación podría hacerse nugatorio, vacío, si la instrucción no se impartiese en su lengua (p. 12).

Con anterioridad a la ratificación de estos convenios internacionales, los diferentes gobiernos habian promulgado leyes y decretos referentes a la conservación, revitalización y difusión de las lenguas y culturas autóctonas y a la educación del niño indigena.

Entre los más importantes están el Decreto Ejecutivo № 22072 de 1993, que crea el Subsistema de Educación Indigena, dentro del Ministerio de Educación Pública y en el artículo 2 establece como fines de la educación en las reservas indígenas los siguientes: alfabetizar en lenguas indigenas, preservar los idiomas indígenas, promover el desarrollo y la práctica de los mismos y promover estrategias para el rescate de las lenguas indígenas que se encuentran en proceso de muerte.

Mediante el Decreto Ejecutivo N²3489 de 1994 se crea el Departamento de Educación Indígena del Ministerio de Educación Pública, que en su artículo 54 establece como objetivos de este Departamento: 
"Orientar la contextualización del currículo a las características y necesidades de la población indígena costarricense" y "Promover la cducación bilinguie y pluricultural en las instituciones educativas de las comunidades indigenas".

Debe recordarse, además, la reforma al Artículo 76 de nuestra Constitución Política, la cual establece que:

"El español es el idioma oficial de la Nación. No obstante, el Estado velará por el mantenimiento y cultivo de las lenguas indigenas nacionales" (Reforma Constitucional 7878 del 27 de mayo de 1999).

\section{La enseñanza de las lenguas indígenas en Costa Rica}

A finales de 1990, como iniciativa de la Escuela de Filología de la Universidad de Costa Rica, se inicia un proyecto de enseñanza de la lengua boruca, en la Escuela Doris Stone, del territorio indígena Boruca. Se crean las condiciones para que una persona de la comunidad imparta lecciones de lengua boruca, como segunda lengua, a los niños de la escuela.

El programa fue tomando cuerpo y fue asumido por el Departamento de Educación Indígena en 1995, año en que inició sus, funciones este Departamento.

En 1997, mediante la resolución 34-97, el Consejo Superior de Educación establece como parte del plan de estudios de las escuelas indígenas dos asignaturas: lengua indígena, con tres lecciones semanales y cultura indígena, con dos lecciones semanales.

Los objetivos del programa de Enseñanza de las Lenguas Indígenas son los siguientes:

- Revitalizar y difundir las lenguas indigenas del país mediante su enseñanza a los niños y jóvenes.

- Desarrollar en los estudiantes habilidades de expresión oral y escrita en la lengua indigena.

- Promover el aprecio por la literatura tradicional indígena.

- Dinamizar procesos de educación bilingüe.

- Facilitar el proceso de transición de la lengua indígena al español, en aquellas comunidades donde la lengua indigena sea la lengua materna.

Estos objetivos se ven apoyados en el programa de Enseñanza de las Culturas Indígenas, que tiene dos grandes objetivos: 
- Promover el fortalecimiento de las culturas indígenas, mediante la enseñanza de los elementos fundamentales de su cultura: historia, filosofia, organización sociopolítica, economía y relación con la naturaleza.

- Fortalecer la identidad étnica y cultural indígena, mediante el conocimiento y revaloración de las prácticas ancestrales, valores, destrezas, habilidades y saberes autóctonos.

Como parte de las actividades del programa de Enseñanza de las Lenguas Indigenas, se desarrollan las siguientes actividades:

1. Enseñanza de la lengua indígena a los niños y jovenes de las instituciones educativas indigenas: en primero y segundo ciclos de la Enseñanza General Básica se imparten tres lecciones semanales de la lengua indigena que corresponde, ya sea como lengua materna o como segunda lengua, y en el tercer ciclo del Colegio Sulàyöm, los jovenes reciben tres lecciones semanales de bribri y tres de cabécar, como segunda lengua.

2. Elaboración de programas de estudio para los cursos de lenguas indígenas. En el caso de la lengua boruca, así como de los cursos de bribri y cabécar del Colegio Sulàyöm, estos programas ya fueron aprobados por el Consejo Superior de Educación. En todos los demás casos, se cuenta con programas de estudio provisionales, en constante revision.

3. Capacitación, en forma integral y constante, a 48 miembros de las comunidades, los cuales se desempeñan como docentes itinerantes de las 6 lenguas indígenas reconocidas.

4. Promoción de la producción de material didáctico para la aplicación de los programas de los cursos.

5. Creación de un marco legal y laboral adecuado para el desempeño de los docentes de lenguas indígenas. El Servicio Civil Docente cre6 el puesto de "Maestro de lengua indigena" con especialidad en cada una de las lenguas reconocidas.

Al presente año, hay 48 maestros itinerantes para la enseñanza de las lenguas indígenas. De ellos 18 enseñan bribri, 18 cabécar, 1 térraba, 3 boruca, 1 malecu y 7 ngäbére.

Todos estos docentes, y también los docentes de los cursos de cultura indígena, son hablantes fluidos de la lengua indígena. Esta es su lengua materna. Todos son miembros de las comunidades indígenas; residen en ellas; han sido formados por sus familias según las normas tradicionales de transmisión de la cultura; poseen conocimientos de agricultura, tradición oral, historia, organización 
familiar, social y política, economía, astronomía, nutrición, artesanía, cosmovisión y otros rasgos fundamentales de las culturas indígenas. Su nivel de escolaridad oscila entre primaria completa y universitaria completa. En promedio es de 8 años.

\section{Obstáculos que enfrenta el programa}

Un programa como el de Enseñanza de las Lenguas Indígenas, y posiblemente cualquier otro que busque dar un espacio a poblaciones minoritarias para la recuperación y transmisión de sus elementos culturales, encuentra como principal obstáculo la falta de preparación y las barreras que en lo administrativo, en lo legal, en lo mental y en lo cultural tenemos para asumir la diversidad cultural.

Los convenios intemacionales contradicen leyes y decretos existentes y aunque su jerarquía jurídica sea superior, muchas veces los conflictos se resuelven al amparo de una ley, de un decreto o inclusive de una disposición.

La carencia de una planificación educativa y cultural, así como la política, permiten la intromisión, en la toma de decisiones, de gente no capacitada para influir en este programa. Esta situación provoca pérdida de tiempo, desánimo y desgaste de los recursos humanos y financieros destinados al programa y es una de las causas que ha impedido, por décadas, la estandarización de los sistemas de escritura de las lenguas indígenas.

La carencia de políticas culturales obstaculiza la coordinación y la delimitación de funciones de múltiples instancias, organizaciones y dependencias gubernamentales, cuyas acciones involucran a las instituciones educativas de los territorios indígenas, y por esa descoordinación se duplican gastos y esfuerzos, se contradicen decisiones técnicas, legales y administrativas y se crean divisiones en el interior de las comunidades indígenas.

Los recursos que se destinan a la producción de materiales didácticos son muy escasos y cuando existen, sólo contemplan el tiraje del material, olvidando que éste debe ser elaborado, ilustrado, revisado, convalidado y editado.

Los docentes de lenguas indigenas han sufrido discriminación por parte de algunos maestros regulares, directores de instituciones y autoridades locales del mismo Ministerio de Educación Pública. Su saber no es acreditado por ninguna institución de educación superior; no se imparte en las universidades; sólo se transmite de generación en generación, como se ha hecho a lo largo de miles de años. El maestro de lengua, que no se considera como tal a raíz de esta realidad, se relega, se autodiscrimina, o lo que es peor, acaba asumiendo como correctas las actitudes de quienes lo desvalorizan. 
Todos son miembros de las comunidades indigenas; residen en ellas; han sido formados por sus familias según las normas tradicionales de transmisión de la cultura; poseen conocimientos de agricultura, tradición oral, historia, organización familiar, social y política, economia, astronomia, nutrición, artesania, cosmovisión y otros rasgos fundamentales de las culturas indigenas. Su nivel de escolaridad oscila entre primaria completa y universitaria completa. En promedio es de 8 años.
Si bien es cierto, mucho se ha avanzado en el mejoramiento de las condiciones de trabajo de quienes imparten los cursos de lenguas indigenas, aún que. da mucho por hacer.

Además, la forma de aprender y enseñar, así como las normas de interacción propias de las culturas indigenas, han sido poco estudiadas, por lo que se ha entendido que el docente de lengua indigena debe enseñar y evaluar como lo hacen los otros maestros, que la lengua indígena debe enseñarse tal y como se enseñan las lenguas modernas y que la integración de estos docentes a las escue-

las debe estar regida por las normas de interacción occidentales.

Uno de los problemas más difíciles que enfrenta el maestro de lengua indigena es la diversidad de niveles que en el uso de las lenguas indígenas muestran los alumnos. Con mucha frecuencia en la misma aula debe atender niños que hablan perfectamente la lengua indigena, niños que la entienden pero no la hablan, niños que no la entienden ni la hablan pero que en sus hogares la oyen hablar y niños que no tienen fuera de la escuela ningún contacto con la lengua indígena.

Si bien es cierto la legislación indígena existente compromete al Estado a desarrollar una educación bilingüe, esto no ha sido posible por la misma carencia de una política educativa, principalmente en lo referente a la atención de la diversidad cultural, la escasez de personal dentro del mismo Departamento de Educación Indígena y la condición monolingüe de un gran número de los maestros regulares que atienden las instituciones educativas indígenas. La educación bilingüe vendría a fortalecer y complementar el programa de Enseñanza de las Lenguas Indígenas y, sobre todo, permitiría un gran crecimiento de estas lenguas. 


\section{Expectativas}

En los años próximos se espera resolver algunas de las carencias y limitaciones del programa, como son las siguientes:

1. Estandarizar los sistemas de escritura y de las ortografías de todas las lenguas indígenas. En este sentido, se ha avanzado bastante con los ngäbes y con los malecus.

2. Contar con todos los programas aprobados por el Consejo Superior de Educación, para la enseñanza de las lenguas indígenas como lenguas maternas y como segundas lenguas, en todos los niveles de la Enseñanza General Básica.

3. Lograr una estrategia de atención de la diversidad lingüística que pueda ser puesta en práctica en las instituciones educativas en las que los niños hablan diferentes lenguas, o muestran diversos niveles de manejo y de uso de las lenguas indígenas. Esta estrategia también deberá resolver la desatención que sufren los niños que asisten a escuelas que están fuera de los territorios indígenas.

4. Incrementar y coordinar la producción de libros de texto para el desarrollo de los programas en todos los niveles.

5. Garantizar la estabilidad laboral de los maestros de lenguas indígenas.

6. Capacitar a los docentes de lenguas indígenas para que sean ellos los que asuman la conducción y ejecución del programa de Enseñanza de las Lenguas Indígenas, desde sus propias expectativas y como miembros de las comunidades indígenas.

7. Impulsar la educación bilingüe en las comunidades que reúnen las condiciones para el desarrollo de este tipo de programas. 
Anexos

Cuadro $\mathrm{N}^{\circ} 1$

Ubicación de la población indígena por provincia

PROVINCIA

POBLACIÓN

INDÍGENA
\% POBLACIÓN INDÍGENA
SAN JOSÉ

ALAJUELA

CARTAGO

HEREDIA

GUANACASTE

PUNTARENAS

LIMÓN

TOTAL
920

3.467

4.261

2.213

4.663

15.034

25.016

63.874
$0,7 \%$

$0,5 \%$

$1,0 \%$

$0,9 \%$

$1.8 \%$

$4,2 \%$

$7,4 \%$

$1,7 \%$

Fuente: INEC. Instituto Nacional de Estadística y Censo. CENSO 2000.

\section{Cuadro $\mathrm{N}^{\circ} 2$}

Población indígena que vive en los territorios indígenas, según grupo cultural

PUEBLO

CABÉCARES

BRIBRIS

BRUNCAS O BORUCAS

GUAYMÍES

HUETARES

MALECUS O GUATUSOS

CHOROTEGAS

TÉRRABAS O TERIBES

TOTAL
POBLACIÓN EN TERRITORIO INDÍGENA

Fuente: INEC. Instituto Nacional de Estadística y Censo. CENSO 2000.

9.861

9.636

2.017

2.563

1.006

460

868

621

27.032 